\title{
The September 5, 2004 off the Kii Peninsula earthquakes as a composition of bending and collision
}

\author{
Tetsuzo Seno \\ Earthquake Research Institute, University of Tokyo, Tokyo 113-0031, Japan
}

(Received November 30, 2004; Revised March 23, 2005; Accepted April 11, 2005)

\begin{abstract}
The 2004 off the Kii Peninsula earthquakes ruptured the subducting Philippine Sea plate near the axis of the Nankai Trough. A series of major events (the fore- and mainshocks with $\mathbf{M}_{w}>7$ ) showed very peculiar rupture characteristics. The depth extent of the foreshock is around $12-23 \mathrm{~km}$ below the sea surface; in contrast, that of the mainshock is around 7-17 km, shallower and closer to the upper surface of the plate than the foreshock. The focal mechanism of the foreshock is almost pure reverse faulting, with a $P$-axis directing roughly $\mathrm{N}-\mathrm{S}$, that is rotated clockwise by $20-25^{\circ}$ from the trough normal. In contrast, the mainshock involved a significant component of strike-slip faulting, with a similar $P$-axis. The OBS survey revealed a double layer of the aftershock activity and the upper NW trending layer contains aftershocks with strike-slip focal mechanisms. These features indicate that the compressional and tensional stress domains due to bending are significantly modified by tectonic stress disturbance and produced the fore- and mainshock ruptures deviated from simple reverse and normal faulting. I show that a supposed N-S compressional stress, which might be produced by the collision south of the Izu Peninsula, can rotate the principal stress axes and change the stress type, which are consistent with the $P$-axes of these events and the strike-slip component for the mainshock. The complex rupture mode of the mainshock might have been produced by superposition of the depth-dependent tensional bending stress in the upper half of the lithosphere and the collisional stress. This collisional stress should be comparable to the bending stresses in magnitude, which is much larger than the stress perturbation caused by nearby interplate locking.
\end{abstract}

Key words: Trench-outer rise, bending, interplate locking, lithosphere, neutral plane, Izu Peninsula, collision, Zenisu Ridge.

\section{Introduction}

Within an oceanic plate, earthquakes often occur in the trench-outer rise region prior to subduction. Shallow normal fault events are common, but deeper reverse fault events are not rare (Chapple and Forsyth, 1979; Christensen and Ruff, 1988; Seno and Yamanaka, 1996). Figure 1(a) shows a spatial distribution of such trench-outer rise events, with well-constrained focal depths, in the circum-Pacific region. In Fig. 1(b), their focal depths or depth extents of ruptures are plotted versus plate ages at their epicenters; normal and reverse faults are shown by open and closed circles (bars), respectively (Seno and Yamanaka, 1996). The normal fault events are distributed above the reverse fault ones, consistent with the idea that they are occurring due to bending of oceanic plates beneath the trench-outer rise. The lower limit of the focal depths corresponds to the $750^{\circ} \mathrm{C}$ isotherm of the cooling plate model (Parsons and Sclater, 1977), which represents the bottom of the lithosphere, and conforms to the similar depth distribution of oceanic intraplate earthquakes (Wiens and Stein, 1983).

Lay et al. (1989) pointed out that reverse fault events tend to occur prior to, and, in contrast, normal fault events tend to occur after, a large nearby interplate earthquake. This

Copy right(c) The Society of Geomagnetism and Earth, Planetary and Space Sciences (SGEPSS); The Seismological Society of Japan; The Volcanological Society of Japan; The Geodetic Society of Japan; The Japanese Society for Planetary Sciences; TERRAPUB. suggests that locking and unlocking at the plate interface in a rupture zone of a large interplate earthquake causes some disturbance to bending stresses beneath the trench-outer rise region. However, the lack of any significant shift of the neutral plane between normal and reverse faults (Fig. 1(b)) suggests that magnitude of such stress disturbance is likely to be much smaller than that of the bending stresses, which amounts to several hundred MPa (Caldwell et al., 1976; see also discussion in Seno and Yamanaka (1996)).

Two large earthquakes, a foreshock and a mainshock of M 7.1 and M 7.4, respectively, after Japan Meteorological Agency (JMA), occurred on Sept. 5, 2004 southeast off the Kii Peninsula near the Nankai Trough axis (Fig. 2). The aftershock distribution revealed by the OBS survey conducted after these events (Sakai et al., 2004) and their nodal planes with dip angles amounting to $\sim 40^{\circ}$ (Centroid moment tensor (CMT) solutions determined by National Research Institute for Earth Science and Disaster Prevention (NIED), JMA and Harvard University, and individual studies by Yamanaka (2004), Yagi (2004) and Hara (2005)) clearly indicate that they have occurred within the subducting Philippine Sea plate (PHS) beneath the trench-outer rise region. The age of the PHS at the focal region is $\sim 20 \mathrm{Ma}$ (Okino et al., 1994), which predicts the lithosphere thickness to be $\sim 25 \mathrm{~km}$ based on the $750^{\circ} \mathrm{C}$ isotherm in Fig. 1(b). The effective elastic thickness of the PHS revealed by the seafloor topography along the Nankai Trough (Yoshioka and Ito, 
(a)

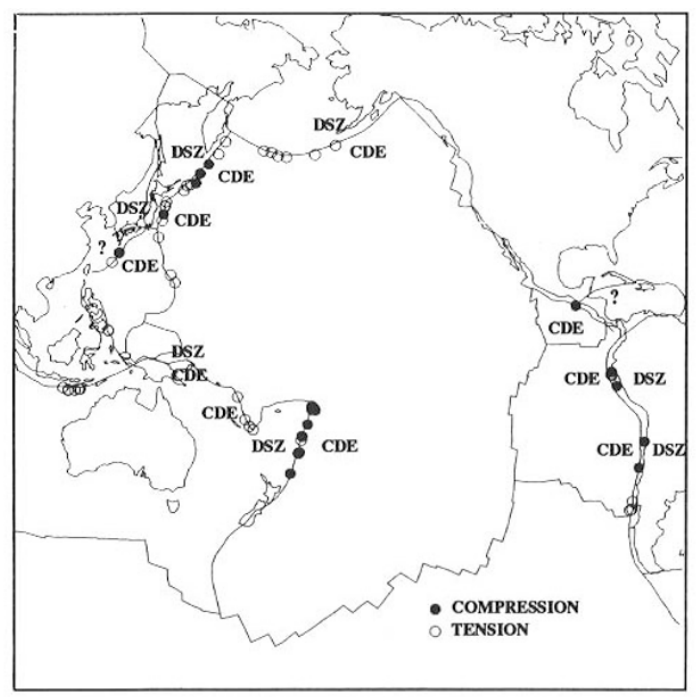

(b)

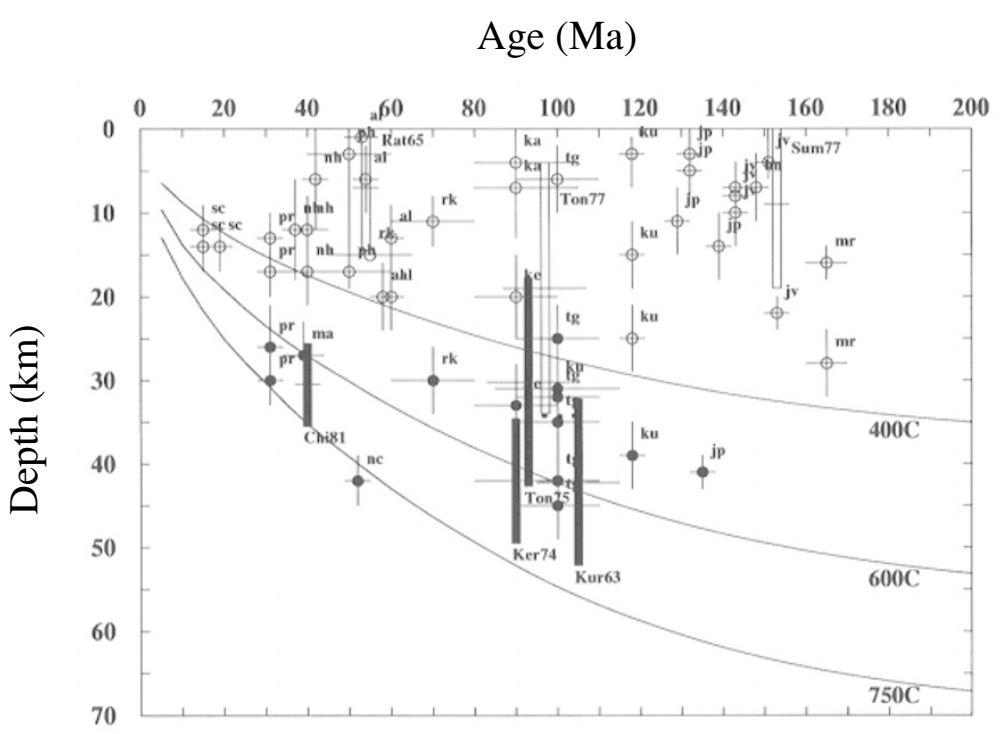

Fig. 1. (a) Spatial distribution of the trench-outer rise evens with well-constrained focal depths (Seno and Yamanaka, 1996). Normal and reverse fault earthquakes are labeled by open and closed circles, respectively. The location where a double seismic zone is seen at intermediate depths and that where a compressional deep event is seen in the trench-outer rise are labeled by "DSZ" and "CDE", respectively. (b) Depth distribution of the trench-outer rise events with well-constrained focal depths versus the age of the ocean floor at their epicenters (Seno and Yamanaka, 1996). Normal and reverse fault earthquakes are labeled by open and closed circles (or bars for large events), respectively. The normal fault events are located above the reverse ones. The maximum depth of the events corresponds to the $750^{\circ} \mathrm{C}$ isotherm of the plate model (Parsons and Sclater, 1977).

2001 ) is $\sim 35 \mathrm{~km}$ for this age, which is larger than the lithosphere thickness estimated above. This is not unexpected because the effective elastic thickness covers not only a brittle part, but also a ductile part of the plate, which supports some of the bending stresses.

These events, therefore, provide an opportunity to examine whether the rupture extents of these events have extended up to near the surface of the plate or not in order to test the Seno and Yamanaka's (1996) inference for the magnitude of tectonic stress disturbance caused by locking or unlocking of a nearby plate interface or by whatever sources. In this study, I try to conduct this on the basis of available studies of rupture processes and focal mechanisms of these events and depth distribution of aftershocks. I show that stress disturbance is significant and its magnitude is comparable to bending stresses. I discuss possible sources of such unusual stress disturbance in terms of plate driving forces in the region and collision occurring south of the Izu Peninsula.

\section{Depth Extent of the Rupture Zones}

Depth extents of the rupture zones for the fore- and mainshocks based on the study of rupture processes using farfield body waves (Yagi, 2004) are plotted in the lithospheric 


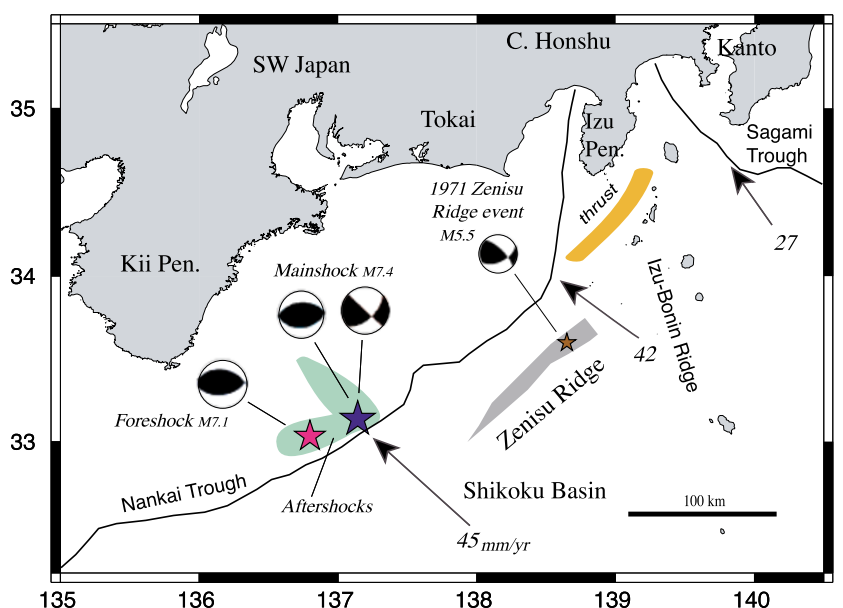

Fig. 2. Tectonic map of Southwest Japan-central Honshu. The Philippine Sea plate is subducting beneath Kanto from the Sagami Trough and beneath Southwest Japan along the Nankai Trough; the relative plate motions are from Seno et al. (1993) and Seno et al. (1996). The Izu-Bonin volcanic ridge is colliding with central Honshu. An incipient thrust inferred south of the Izu Peninsula (Seno, 2005b; Taira et al., 1992) is indicated by orange bar. The epicentral locations of the foreand mainshocks of the 2004 off the Kii Peninsula earthquakes are shown by red and blue stars, respectively. Aftershock activity associated with these shocks (JMA, 2004) is shaded by green. The epicentral location of the 1971 Zenisu Ridge earthquake is shown by brown star. The lower hemispheres of the focal mechanisms of the 2004 events (Yagi, 2004) and that of the 1971 event (Seno, 1987) are also shown. The magnitudes and epicenters of these events shown in this figure are after JMA.

column of the PHS (Fig. 3). The areas that have slipped more than $50 \%$ of the maximum slip are taken as rupture areas, and are converted to the depth extent; even if I take a smaller fraction of the maximum slip as a threshold, the results do not change much. The depth extent of the foreshock is $12-23 \mathrm{~km}$ below the sea surface; in contrast, that of the mainshock is $7-17 \mathrm{~km}$, which is shallower and closer to the upper surface of the plate than the foreshock. The hypocenter of the mainshock (star) departs from its rupture extent. This kind of departure sometimes happens in body-wave analyses of rupture processes of large earthquakes (See the case of the 1968 Tokachi-oki and 1994 Sanriku-haruka-oki earthquakes off N. Honshu in Nagai et al. (2001) for an example). The depth extents of the rupture zones by Yamanaka (2004) are by a few km shallower than those shown in Fig. 2, but do not differ much. The aftershock distribution revealed by the OBS survey (Sakai et al., 2004) shows two separate zones, the shallow one around a $10 \mathrm{~km}$ depth in the oceanic crust and the deep one around a $20 \mathrm{~km}$ depth in the mantle; these are also plotted in this figure. Although Ito et al. (2005) located a group of aftershocks shallower than a $5 \mathrm{~km}$ depth, I did not use their results because accuracy of hypocentral determination by the OBS is much better than that by the inland stations.

\section{Focal Mechanisms}

CMT solutions of these events determined by NIED, JMA, and Harvard University show that their ruptures are dominantly of reverse-fault type. However, closer examinations of the rupture processes show that the rupture of the mainshock is more complicated. Hara (2005) analyzed

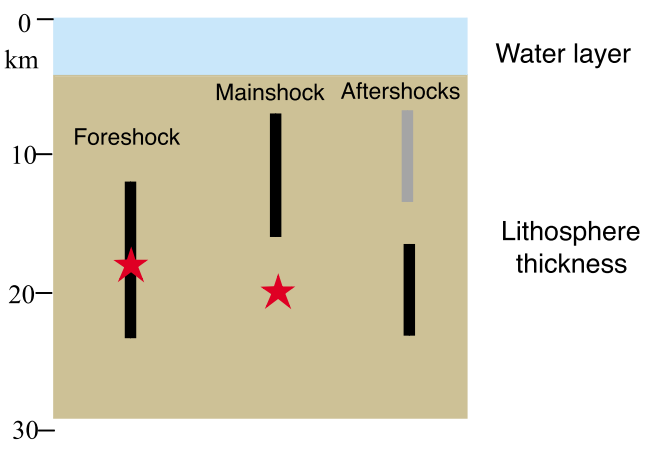

Fig. 3. Depth extent of the rupture zones of the fore- and mainshocks plotted in the column of the plate with a water layer. The rupture extents are from Yagi (2004); the foreshock is between $23 \mathrm{~km}$ to $12 \mathrm{~km}$, and that of the mainshock is between 17 and $7 \mathrm{~km}$. The lithosphere thickness of the plate is $25 \mathrm{~km}$ (Seno and Yamanaka, 1996). The hypocentral depths are indicated by stars. The two zones of the aftershock activity revealed by the OBS surveys (Sakai et al., 2004) are also plotted; the upper and lower zones are distributed in the depth ranges between $6-14 \mathrm{~km}$ and between $16-24 \mathrm{~km}$, respectively.

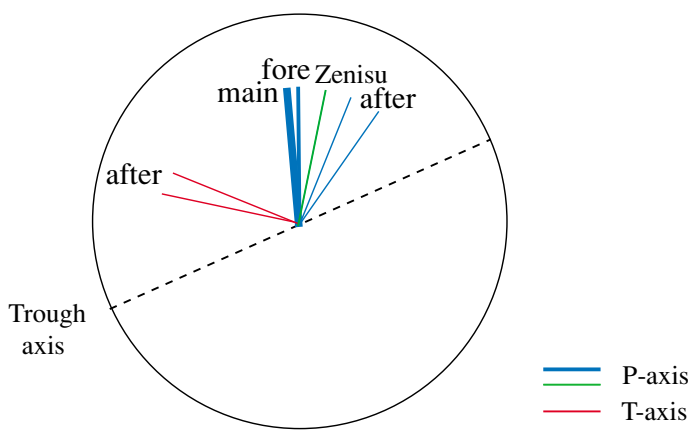

Fig. 4. $\quad P$-axes of the foreshock and the reverse fault-type sub-event of the mainshock (Yagi, 2004) are plotted by thin and thick blue bars, respectively. That of the strike-slip fault-type sub-event of the mainshock is not much different from that of the reverse type (see Fig. 2). The $P$ - and $T$-axes of two aftershocks in the NW trending aftershock zone (JMA, 2004) are plotted by thinnest blue and red bars, respectively. The $P$-axis of the 1971 Zenisu Ridge event (Seno, 1987) is plotted by green bar. The $P$-axes of the aftershocks are rotated clockwisely by $20-30^{\circ}$ from those the fore- and mainshocks.

a time series of the moment tensor components during the rupture of the mainshock using surface waves and showed that the rupture, having started as strike-slip, has changed to reverse faulting after $\sim 20 \mathrm{sec}$. This gives a reason for the large non-double couple component of the CMT solution by Harvard University. Accordingly, Yagi (2004) revised his initial model and introduced additional strike-slip faulting on the fault plane trending northwest with a comparable seismic moment to that of the E-W trending reverse fault. The tsunamis caused by the mainshock are roughly consistent with the rupture on the two faults (Satake et al., 2005; Baba et al., 2005).

The $P$-axis of the reverse fault-type sub-event and that of the foreshock by Yagi (2004) are plotted in Fig. 4; they are almost coincident and directing N-S. That of the strike-slip sub-event of the mainshock is also similar to them (Fig. 2). Because the trend of the trough axis is $\mathrm{N} 64^{\circ} \mathrm{E}$, they are rotated clockwise from the trough normal by $20 \sim 25^{\circ}$.

The $P$-axes of two aftershocks that have occurred within the aftershock zone trending northwest (Fig. 2, green- 
(a) Lower half

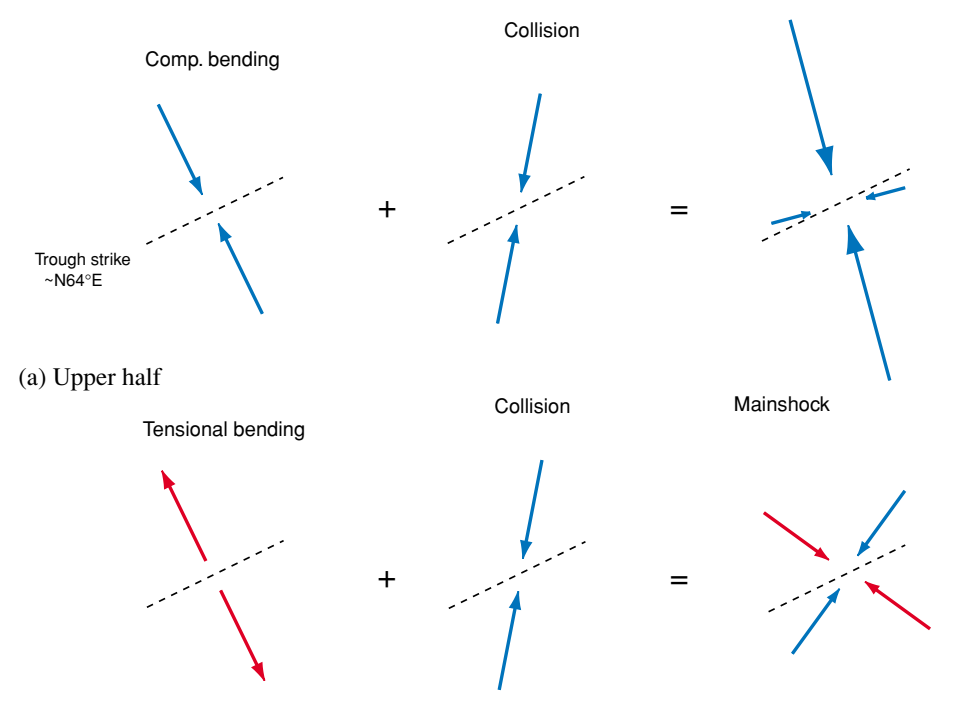

Fig. 5. Change of the principal stress axes of bending by addition of a collisional stress directing N11 ${ }^{\circ} \mathrm{E}$. The magnitude of the collisional stress is assumed to be the same as that of the bending stress. (a) On the compressional bending stress directing normal to the trough axis, the compressional stress is superposed. The resultant stress is of reverse fault-type whose $\sigma_{1}$ is rotated clockwise to N15 ${ }^{\circ} \mathrm{W}$. (b) On the tensional bending stress directing normal to the trough axis, the compressional stress is superposed. The resultant stress is of strike-slip fault-type whose $\sigma_{1}$ is directing to N36. ${ }^{\circ} \mathrm{E}$.

shaded) determined by JMA are also plotted in this figure (thin blue bars). These are likely to have occurred within the shallow layer of the double zone of the aftershocks (Sakai et al., 2004). They are rotated further clockwise from those of the large events by $20-30^{\circ}$. Their $T$-axes are also plotted in this figure (thin red bars) to examine whether they are close to the trough normal or not. Both of the $T$ - and $P$-axes are oblique to the trough normal.

\section{Discussion}

\subsection{Are they bending events?}

I summarize the results obtained seismologically as follows. (1) Although there might be still uncertainties by a few $\mathrm{km}$ in the depth extent of the rupture zones of the 2004 off the Kii Peninsula earthquakes, it is likely that the foreshock ruptured nearly the lower half of the plate beneath the trench-outer rise region. In contrast, the mainshock has ruptured a shallower portion of the plate, i.e., $\sim 5 \mathrm{~km}$ shallower than the depth extent ruptured by the foreshock. The upper and lower layers of the double zone of the aftershock activity revealed by the OBS seems to correspond roughly to the depth extents of the main- and foreshocks, respectively, although there is considerable overlap between them. There is a slight indication that the aseismic surface between these layers is offset to a shallower depth by a few $\mathrm{km}$ than the mid-depth of the lithosphere (Fig. 3), although possible lack of depth resolution of hypocenter determination might have caused this apparent offset. (2) The $P$-axis of these events are roughly directing N-S and rotated clockwise by $20 \sim 25^{\circ}$ from the trench normal. The foreshock is dominantly of reverse fault-type, but the mainshock contains a significant strike-slip component in addition to a reverse fault one. This component is concordant with the NW trending upper layer of the aftershock activity, containing strike-slip mechanisms.
These contrasting features between the fore- and mainshock ruptures and the fact that the aftershock zone revealed by the OBS is evidently separated into double layers suggest that the rupture characteristics reflect different tectonic stress domains at different depths. I assume here that tensional and compressional stress domains have originated in the upper and lower halves of the elastic plate, respectively, near the epicentral area due to bending, and the different rupture mode and depth extent of the fore- and mainshocks are reflecting these two domains. Additional tectonic stress is likely to have overlapped and modified their ruptures from simple reverse and normal faulting. The depth extents might also have been affected and shifted shallower by such a tectonic stress. I investigate below what kind of additional tectonic stresses can be consistent with the observed rupture characteristics.

\subsection{A possible source for the stress disturbance}

Seno (2000) estimated tectonic forces that are driving the PHS motion. The ridge push force for this plate mainly results from the difference in plate thickness between the basins of different ages. This kind of the ridge push does not operate at the focal region of the 2004 events because they are located in the youngest Shikoku Basin. Within the basin, however, there exists a gradient in age, and a minor ridge push force operates due to this age gradient. Because the extinct spreading center in the Shikoku Basin is directing to NNW-SSE and is located south of E. Shikoku, the Shikoku Basin becomes older from the spreading center to the focal region. The age difference of 5 m.y. (Okino et al., 1994) produces a compressional stress of only $\sim 1$ MPa (Parsons and Richter, 1980), however, which is much smaller than the bending stress. Furthermore, because this ridge push is directing parallel to the Nankai Trough, it does not rotate the principal stress axes of bending in the trenchouter rise region. 
Because the subducting PHS slab is as young as $20 \mathrm{Ma}$, the buoyant oceanic crust-harzburgite layer counteracts entirely the negative buoyancy of the lithosphere (Davies, 1992); thus a slab pull force is neither expected in the focal region. This is concordant with the arc-parallel tension of the PHS slab beneath SW Japan (Ukawa, 1982; Noguchi, 1996).

These small magnitudes of the ridge push and slab pull forces result in a small magnitude of the collision force, and thus a small magnitude of the shear stress, acting at the interplate thrust zone (Seno and Yamanaka, 1998; Seno, 1999), consistent with the observed E-W $\sigma_{H \text { max }}$ in the SW Japan forearc (Seno, 1999; Wang and He, 1999). Therefore it can be said that interseismic locking at the interplate thrust such as the rupture zone of the 1944 Tonankai earthquake, even if it may have had triggered the occurrence of the 2004 events, could not be a desired source of stress disturbance for this region suggested in the previous subsection.

Tectonic forces other than the ridge push and slab pull forces should, therefore, be operating to the PHS at the focal area. A force due to collision of the Izu Peninsula against central Honshu might be one of such forces. Complete locking at the shallow interplate thrust in collision zones makes the compressional stress very large, amounting to a few $100 \mathrm{MPa}$ (Seno, 2005a). This type of locking has been inferred at the thrust located tens of $\mathrm{km}$ south of the peninsula (Fig. 2, orange bar), with steady slip on the horizontal detachment to the north beneath the Izu Peninsula at a depth of $20 \mathrm{~km}$ (Seno, 2005b). The collisional stress caused by this locking might affect the PHS further to the west, as indicated by the N-S to NNE-SSW $P$-axes of small shallow events (Fukuyama et al., 2001). The Jan. 3, 1971 event (M 5.5) that occurred beneath the Zenisu Ridge (Fig. 2) would be one of such events. This event occurred at a depth of 35 $\mathrm{km}$ and had a reverse fault focal mechanism with a strikeslip component (Seno, 1987), similar to that of the strikeslip sub-event of the mainshock. The $P$-axis of this event is directed $\mathrm{N} 11^{\circ} \mathrm{E}$ (Fig. 4, green thin bar). I infer that similar stress disturbance may continue further to the west near the focal region of the 2004 events.

However, the focal region of the 2004 events is still more than $100 \mathrm{~km}$ away from the 1971 earthquake. T. Hori (personal comm., 2004) suggested that subduction of ridges such as the paleo-Zenisu ridges beneath the Tokai district might produce a large compressional perturbing stress affecting the focal region of the 2004 events. Although such ridge subduction may be a possible source of the stress disturbance, the magnitude of the differential stress due to ridge subduction would be much smaller than that caused by collision. Otherwise, collision might have been taking place in the Tokai district. At present, I cannot provide any reasonable explanation why a compressional stress disturbance extends such a long distance. However, the fact that the compressional Zenisu Ridge extends very close to the epicentral area of the 2004 events (Fig. 2) indicates that such a disturbance is plausible.

I show here that a N-S compressional stress due to collision can rotate the principal stress axes and change the stress type in the focal region. Let us assume that the ad- ditional compressional stress is directed along the $P$-axis of the 1971 Zenisu Ridge event $\left(\mathrm{N} 11^{\circ} \mathrm{E}\right)$ and its magnitude is the same as the maximum bending stress. Representing these collisional and bending stresses as stress tensors and summing each component of these, the resultant principal stresses are calculated. If the compressional bending stress is summed with the collisional stress, the resultant stress is of reverse fault-type with $\sigma_{1}$ oriented in $\mathrm{N} 15^{\circ} \mathrm{W}$, and magnitudes of $\sigma_{1}$ and $\sigma_{2}$ are 1.6 and 0.4 times that of the bending stress, respectively. On the other hand, If the tensional bending stress is summed with the collisional stress, the resultant stress is of strike-slip fault-type with $\sigma_{1}$ oriented in $\mathrm{N} 36.5^{\circ} \mathrm{E}$, and magnitudes of $\sigma_{1}$ and $\sigma_{3}$ are both 0.79 times that of the bending stress.

The composite stress of the compressional bending and collisional stresses is consistent with the $P$-axis of the foreshock, and that of the tensional bending and collisional stresses is consistent with the strike-slip component of the mainshock. The upper end of the original compressional domain of bending will be shifted shallower, which seems consistent with the apparent upward shift of the neutral plane. It is also expected that, around the original neutral plane of bending, the N-S collisional stress will dominate. Toward the upper surface of the plate, the composite stress approaches the strike-slip type predicted above. This might explain the fact that the mainshock contained both the reverse fault and strike-slip components. If this is true, the difference in principal stress direction between bending and collision, and the depth-dependent bending stress have produced the complex rupture mode of the mainshock. Closer examination of its rupture process, including a spatio-temporal change of the source mechanism, seems necessary to make ascertain this inference.

\subsection{Deep compressional trench-outer rise events and dehydration}

Seno and Yamanaka (1996) noted that where deeper compressional earthquakes occur in the trench-outer rise region, they generally associate double seismic zones landward at intermediate depths; Figure 1(a) shows this association. They proposed that both the compressional deep trench-outer rise events and the lower plane activity of the double seismic zone are caused by the same mechanism, i.e., dehydration embrittlement of serpentinized mantle in the oceanic plate. In other words, paired bending events of normal-reverse faults at the trench-outer rise may be nearsurface manifestation of the double seismic zone at depth.

Beneath the Kii Peninsula, Seno et al. (2001) and Yamasaki and Seno (2003) noted possible existence of a double seismic zone within the PHS slab and discussed it from a viewpoint of dehydration of the serpentinized slab mantle. Recently, Aoki (2003) and Miyoshi and Ishibashi (2004) also recognized a double seismic zone beneath the Kii Peninsula from detailed investigation of seismicity. It is, therefore, no surprise for deep compressional events such as the 2004 foreshock to have occurred in the region southeast off the Kii Peninsula. Seno et al. (2001) proposed that this part of the Shikoku Basin lithosphere was serpentinized by the backarc volcanism behind the Izu-Bonin Ridge (See figure 9 of Seno et al. (2001)). 


\section{Conclusions}

The fore- and mainshocks of the 2004 off the Kii Peninsula earthquakes provide a key to understand the influence of tectonic stresses on the bending stresses in the focal region of these events. The $P$-axes of the fore- and mainshocks are significantly rotated from the trench normal; the neutral plane also seems to have shifted slightly upward. The mainshock have involved a significant strike-slip component. I show that a N-S compressive force, possibly due to the collision in the south of the Izu Peninsula, would have perturbed the bending stresses and produced rotation of the principal stress axes, and changed the stress type, which are consistent with the observed $P$-axes of the events and the strike-slip component of the mainshock. The complex rupture mode of the mainshock might have been produced by superposition of the collisional stress on the depthdependent tensional bending stress in the upper half of the lithosphere. The magnitude of this collision force should be comparable to that of the bending stresses, amounting to a few $100 \mathrm{MPa}$. The stresses due to interplate locking at the subduction zone thrust along the Nankai Trough are by far smaller ( $\sim 1 \mathrm{MPa}$ at most) than these stresses.

Acknowledgments. Thanks are to two anonymous reviewers for critical comments, and Atsuki Kubo, Takane Hori, Hiroo Kanamori, Yoji Kobayashi for discussion, and to Yoshiko Yamanaka, Yuji Yagi, and Shin'ichi Sakai for details of their analyses of the rupture processes and aftershocks.

\section{References}

Aoki, H., Geometry of the subducted Philippine Sea plate and its continuity, Rep. Tono Res. Inst. Earthquake Sci., Seq. No. 12, 43-51, 2003 (in Japanese).

Baba, T., P. R. Cummins, and T. Hori, Compound fault rupture during the 2004 off the Kii Peninsula earthquake (M 7.4) inferred from highly resolved coseismic sea-surface deformation, Earth Planets Space, 57, 167-172, 2005.

Caldwell, J. G., W. F. Haxby, D. E. Karig, and D. L. Turcotte, On the applicability of a universal elastic trench profile, Earth Planet. Sci. Lett., 31, 239-246, 1976.

Chapple, W. M. and D. W. Forsyth, Earthquakes and bending of plates at trenches, J. Geophys. Res., 84, 6729-6749, 1979.

Christensen, D. H. and L. J. Ruff, Seismic coupling and outer-rise earthquakes, J. Geophys. Res., 93, 13421-13444, 1988.

Davies, G. F., On the emergence of plate tectonics, Geology, 20, 963-966, 1992.

Fukuyama, E., A. Kubo, H. Kawai, and K. Nonomura, Seismic remote monitoring of stress field, Earth Planets Space, 53, 1021-1026, 2001.

Hara, T., Change of the source mechanism of the mainshock of the 2004 off the Kii Peninsula earthquakes inferred from long period body wave data, Earth Planets Space, 57, 179-183, 2005.

Ito, Y., T. Matsumoto, H. Kimura, H. Matsubayashi, K. Obara, and S. Sekiguchi, Spatial distribution of centroid moment tensor solutions for the 2004 off Kii peninsula earthquakes, Earth Planets Space, 57, 351$356,2005$.

Japan Meteorological Agency (JMA), http://www.jishin.go.jp/main/ chousa/04oct_kiihantou/p03.htm, 2004.

Lay, T., D. H. Christensen, L. Astiz, and H. Kanamori, Temporal variation of large intraplate earthquakes in coupled subduction zones, Phys. Earth Planet. Inter., 54, 258-312, 1989.

Miyoshi, T. and K. Ishibashi, Geometry of the seismic Philippine Sea slab beneath the region from Ise Bay to western Shikoku, Southwest Japan, Jisin, 57, 139-152, 2004 (in Japanese).

Nagai, R., M. Kikuchi, and Y. Yamanaka, Comparative study on the source processes of reccurrent large earthquakes in Sanriku-oki region: the 1968 Tokachi-oki earthquake and the 1994 Sanriku-oki earthquake, Jisin, 54, 267-280, 2001 (in Japanese)

National Research Institute for Earth Science and Disaster Prevension, http://www.hinet.bosai.go.jp/topics/se-off-kii0409/, 2004.
Noguchi, S., Geometry of the Philippine Sea slab and the convergent tectonics in the Tokai District, Japan, Jisin, 49, 295-325, 1996 (in Japanese).

Okino, K., Y. Shimakawa, and S. Nagano, Evolution of the Shikoku Basin, J. Geomag. Geoelectr., 46, 463-479, 1994.

Parsons, B. and J. G. Sclater, An analysis of the variation of ocean floor bathymentry and heat flow with age, J. Geophys. Res., 82, 803-827, 1977.

Parsons, B. and F. M. Richter, A relation between the driving force and geoid anomaly associated with mid-oceanic ridges, Earth Planet. Sci. Lett., 51, 445-450, 1980.

Sakai, S., M. Shinohara, T. Yamada, H. Hagiwara, T. Kanazawa, K. Obana, S. Kodaira, M. Kinoshita, and Y. Kaneda, Temporary aftershock observation using OBS of the 2004 Kii-hanto-nanto-oki earthquakes, A talk given at the monthly meeting of the Earthq. Res. Inst., Univ. Tokyo, Oct. 16, 2004, 2004

Satake, K., T. Baba, K. Hirata, S. Iwasaki, T. Kato, S. Koshimura, J. Takenaka, and Y. Terada, Tsunami source of the 2004 off the Kii Peninsula earthquakes inferred from offshore tsunami and coastal tide gauges, Earth Planets Space, 57, 173-178, 2005.

Seno, T., Focal mechanism and depth of the 1971 January 3 earthquake (M5.5) which occurred near the Zenisu Ridge off central HonshuImplications for the Philippine Sea palte thickness at the western margin of the Izu Ridge, Jisin, 40, 629-632, 1987 (in Japanese).

Seno, T., Syntheses of the regional stress fields of the Japanese islands, The Island Arc, 8, 66-79, 1999.

Seno, T., Why the Philippine Sea plate moves as it does, J. Geol. Soc. Phil., 55, 105-117, 2000.

Seno, T., Collision vs. subduction: the importance of slab dehydration, in The Seismogenic Zone of Subduction Thrust Faults, edited by T. Dixon and J. C. Moore, Columbia Univ Press, 2005a (in press).

Seno, T., Izu detachment hypothesis: A proposal of a unified cause for the Miyake-Kozu event and the Tokai slow event, Earth Planets Space, 2005 b (in press).

Seno, T. and Y. Yamanaka, Double seismic zones, compressional deep trench-outer rise events and superplumes, in Subduction Top to Bottom, edited by G. E. Bebout, D. W. Scholl, S. H. Kirby, and J. P. Platt, Geophys. Monogr, AGU, Washington D. C., 96, pp. 347-355, 1996.

Seno, T. and Y. Yamanaka, Arc stresses determined by slabs: Implications for mechanisms of back-arc spreading, Geophys. Res. Lett., 25, 3227 3230, 1998.

Seno. T., S. Stein, and A. E. Gripp, A model for the motion of the Philippine Sea plate consistent with NUVEL-1 and geological data, J. Geophys. Res., 98, 17941-17948, 1993.

Seno, T., T. Sakurai, and S. Stein, Can the Okhotsk plate be discriminated from the North American plate?, J. Geophys. Res., 101, 11305-11315, 1996

Seno, T., D. Zhao, Y. Kobayashi, and M. Nakamura, Dehydration in serpentinized slab mantle: Seismic evidence from southwest Japan, Earth Planets Space, 53, 861-871, 2001.

Taira, A., K. T. Pickering, B. F. Windley, and W. Soh, Accretion of Japanese island arcs and implications for the origin of Archean greenstone belts, Tectonics, 11, 1224-1244, 1992

Ukawa, M., Lateral stretching of the Philippine sea plate subducting along the Nankai-Suruga Trough, Tectonics, 1, 543-571, 1982.

Wang, K. and J. He, Mechanics of low-stress forearcs: Nankai and Cascadia, J. Geophys. Res., 104, 15191-15205, 1999.

Wiens, D. A. and S. Stein, Age dependence of oceanic intraplate seismicity and implications for lithospheric evolution, J. Geophys. Res., 88, 64556468, 1983

Yagi, Y., http://iisee.kenken.go.jp/staff/yagi/eq/Japan20040905/ Japan20040905_1-j.html, 2004.

Yamanaka, Y., http://www.eri.u-tokyo.ac.jp/sanchu/Seismo_Note/2004/ EIC152.html, 2004

Yamasaki, T. and T. Seno, Double seismic zones and dehydration embrittlement, J. Geophys. Res., 108(B4), 2212, doi:10.1029/2002JB001918, 2003

Yoshioka, S. and Y. Ito, Lateral variations of effective elastic thickness of the subducting Phillippine Sea plate along the Nankai trough, Earth Planets Space, 53, 261-273, 2001.

T. Seno (e-mail: seno@eri.u-tokyo.ac.jp) 